\title{
Consensus on the Prevention, Screening, Early Diagnosis and Treatment of Colorectal Tumors in China: Chinese Society of Gastroenterology, October 14-15, 2011, Shanghai, China
}

\author{
Jing-Yuan Fang ${ }^{a-d}$ Shu Zheng ${ }^{\text {e, }}{ }^{f}$ Bo Jiang ${ }^{\text {h }}$ Mao-De Laig \\ Dian-Chun Fang ${ }^{i}$ Ying Han $^{j}$ Qian-Jiu Sheng ${ }^{j}$ Jing-Nan Li $^{\mathrm{k}}$ \\ Ying-Xuan Chen ${ }^{\text {a-d }}$ Qin-Yan Gao ${ }^{a-d}$ \\ a Division of Gastroenterology and Hepatology, Renji Hospital, Shanghai Jiaotong \\ University School of Medicine, ${ }^{b}$ Shanghai Institute of Digestive Disease, ${ }^{c}$ Key Laboratory \\ of Gastroenterology and Hepatology, Ministry of Health, and dState Key Laboratory of \\ Oncogene and Related Genes, Shanghai Jiaotong University, Shanghai; ${ }^{\mathrm{e} K e y}$ Laboratory of \\ Cancer Prevention and Intervention of China National Ministry of Education, Key Laboratory of \\ Molecular Biology in Medical Sciences of Zhejiang Province, Cancer Institute, ${ }^{f}$ Second Affiliated \\ Hospital of Zhejiang University School of Medicine, and ${ }^{9}$ Department of Pathology and \\ Pathophysiology, Zhejiang University School of Medicine, Hangzhou; ${ }^{\mathrm{h}}$ Guangdong Provincial \\ Key Laboratory of Gastroenterology, Department of Gastroenterology, Nanfang Hospital, \\ Southern Medical University, Guangzhou; 'Department of Gastroenterology, Southwest Hospital, \\ Third Military Medical University, Chongqing; ${ }^{j}$ Department of Gastroenterology, General

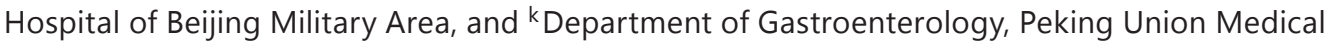 \\ College Hospital, Peking Union Medical College, Chinese Academy of Medical Sciences, Beijing, \\ China
}

\section{Key Words}

Colorectal tumors · Prevention · Screening · Early diagnosis · Treatment

\begin{abstract}
Background: Colorectal cancer (CRC) is steadily increasing in China. Colorectal adenoma (CRA) is the most important precancerous disease of CRC. Screening for colorectal tumors can aid early diagnosis. Advances in endoscopic mucosal resection and endoscopic submucosal dissection can aid the early treatment of colorectal tumors. Furthermore, because of high risk of recurrence after removal of adenomas under endoscopy, factors contributing to recurrence, the follow-up mode and the interval established, and the feasibility of application and the time of various chemical preventions should be concerned. However, a relevant consensus on the screening, early diagnosis and treatment, and prevention of colorectal tumors in China is lacking.
\end{abstract}


Summary: The consensus recommendations include epidemiology, pathology, screening, early diagnosis, endoscopic treatment, monitoring and follow-up, and chemoprevention of colorectal tumors in China.

Key Message: This is the first consensus on the prevention, screening, early diagnosis and treatment of CRA and CRC in China based on evidence in the literature and on local data.

Practical Implications: Through reviewing the literature, regional data and passing the consensus by an anonymous vote, gastroenterology experts from all over China launch the consensus recommendations in Shanghai. The incidence and mortality of CRC in China has increased, and the incidence or detection rate of CRA has increased rapidly. Screening for colorectal tumors should be performed at age 50-74 years. Preliminary screening should be undertaken to find persons at high risk, followed by colonoscopy. A screening cycle of 3 years is recommended for persistent interventions. Opportunistic screening is a mode suitable for the current healthcare system and national situation. Colonoscopy combined with pathological examination is the standard method for the diagnosis of colorectal tumors. CRA removal under endoscopy can prevent CRC to some extent, but CRA has an obvious recurrence trend. The follow-up interval after the removal or surgery of colorectal tumors should be different with lesions. Primary prevention of CRA includes improved diet with more fiber, supplements containing calcium and vitamin D, supplements containing folic acid for those with low hemoglobin levels, and cessation of tobacco smoking. Non-steroidal anti-inflammatory drugs and selective cyclooxygenase-2 inhibitors have been recognized to prevent recurrence after adenoma removal.

(c) 2014 S. Karger AG, Basel

Colorectal cancer (CRC) is common in China, just as it is in 'developed' western countries. With improvements in the standard of living and changes in eating habits, the incidence of CRC has been increasing in China, especially in cities. Colorectal adenoma (CRA) is the most important precancerous disease of CRC [1-3]. Colorectal tumors usually include CRC and CRA.

Scholars have paid considerable attention to the screening for colorectal tumors, which can aid early diagnosis. In general, it mainly includes fecal occult blood test (FOBT), endoscopy (colonoscopy and sigmoidoscopy), imaging tests and laboratory analyses. With technical developments such as confocal laser endoscopy, narrow-band imaging (NBI), magnifying endoscopy and chromoendoscopy, the identification of flat adenomas can be improved. In addition, advances in endoscopic mucosal resection and endoscopic submucosal dissection can aid the early treatment of colorectal tumors. The removal of adenomas under endoscopy can effectively prevent CRC occurrence, but its recurrence after removal has many disadvantages. Therefore, the factors that may cause recurrence should be analyzed, the follow-up mode and the interval established, and the feasibility of application and the time of various chemical preventions discussed.

The international consensus on colorectal tumors includes guidelines formulated by the American Gastroenterological Association/American Society for Gastrointestinal Endoscopy (AGA/ASGE) [4] and by the Asia-Pacific Association for Gynecologic Endoscopy (APAGE) [5, 6]. However, the relevant consensus on the screening, early diagnosis and treatment, and prevention of colorectal tumors in China is lacking. Therefore, the seminar 'Consensus on the Prevention, Screening, Early Diagnosis and Treatment of Colorectal Tumors in China' was held in Shanghai on October 14-15, 2011. This seminar was sponsored by the Tumor Cooperative Group, the Chinese Society of Digestive Diseases and the Chinese Medical Association. The seminar was undertaken by Division of Gastroenterology and Hepatology, Renji Hospital, Shanghai Jiaotong University School of Medicine and Shanghai Institute of Digestive Diseases, 
all of which are based in Shanghai, China. The experts had repeated discussions and undertook revisions on the draft. They then passed the consensus by secret ballot. The voting options were: (1) totally agree; (2) agree but have some reservations; (3) agree but have greater reservations; (4) disagree but have reservations; (5) totally disagree. If option 1 passed by $>2 / 3$ or option $1+$ option 2 passed by $>85 \%$, the term was considered to have been passed. The full text is described below.

\section{Epidemic Situation of Colorectal Tumors in China}

\section{The incidence and mortality of CRC in China has increased.}

With changes in diets, the number of new cases of CRC in China has increased. Data have shown that the incidence of CRC (crude rate) of males in cancer registration areas increased from $25.6 / 100,000$ in 2003 to 32.5/100,000 in 2007, whereas that of females increased from $22.7 / 100,000$ to $26.7 / 100,000$. The mortality of males due to CRC increased from $12.3 / 100,000$ in 2003 to $15.6 / 100,000$ in 2007, whereas that of females increased from 11.1/100,000 to $12.7 / 100,000$ [7].

\section{The incidence or detection rate of CRA has increased rapidly.}

Several scholars have analyzed the epidemics of CRC and CRA. European researchers analyzed 917 cases with an average risk of CRC aged 50-75 years old with colonoscopy. They found the percentages of cases with CRA, advanced adenoma and CRC to be 21.3, 6.7 and $1.2 \%$, respectively, whereas those among 183 cases aged 40-49 years were found to be 9.8 , 1.1 and $0 \%$, respectively [8]. A total of 3,121 American patients with abdominal symptoms aged 50-75 years underwent colonoscopy, and the percentage of cases with villous adenomas $>1 \mathrm{~cm}$ was $7.9 \%$, that of cases with advanced adenoma accompanied by a high level of intraepithelial neoplasia (IEN; a detailed definition is given below) was 1.6\%, and that of cases with invasive CRC was $1 \%[3,9]$. After a 5.3-year follow-up of 1,256 cases without polyps under colonoscopy, other scholars found that the percentage of cases with CRA, advanced adenoma and CRC was $16,1.3$ and $0 \%$, respectively [10]. A multicenter retrospective study in China confirmed that for urban residents with abdominal symptoms who received colonoscopy within 20 years $(157,943$, i.e. 26,026 in 1991-2000 and 131,917 in 2001-2010), the number of cases with advanced adenoma increased by 1.88 -fold compared to the previous decade $(\mathrm{p}<0.01)$, whereas cases with CRC increased by 66\% [11]. That study reported that the incidence of adenoma was increased significantly in subjects aged 50 years $[11,12]$.

Advanced adenomas or high-risk adenomas are more dangerous. Their presence can be confirmed if any one of the following three conditions are met: (i) diameter of polyp or lesion $\geq 10 \mathrm{~mm}$; (ii) villous structure in villous adenoma or mixed adenomas $>25 \%$; (iii) the case is associated with high-level IEN $[8,9]$.

\section{Pathology of Colorectal Tumors}

3. CRC is a malignant tumor in the mucosal epithelium, including carcinoma in situ, invasive and metastatic carcinoma.

According to the latest definition from the World Health Organization (WHO), CRC is an epithelial tumor of the colon that can penetrate the muscularis mucosa and infiltrate into the submucosa, which emphasizes the fact that a diagnosis of CRC should have anatomical evidence. Although the morphology is malignant, cases in whom the muscularis mucosa is not penetrated cannot be considered to be 'cancer' or the term 'cancer' should be avoided [13]. 
Carcinoma in situ is common in the clinic, but it is suggested that this term should be abandoned and gradually replaced by the WHO definition stated above.

4. CRC is divided into five histological subtypes: adenocarcinoma, adenosquamous carcinoma, spindle cell carcinoma, squamous cell carcinoma and undifferentiated carcinoma. A mucosal biopsy specimen is employed to ascertain whether it is a benign or malignant lesion.

CRA has six subtypes: cribriform adenoma, medullary carcinoma, micropapillary carcinoma, mucinous adenoma, serrated adenoma and signet ring cell carcinoma. Other types are very rare, including the papillary adenoma rich in Paneth cells, choriocarcinoma and clear cell carcinoma $[13,14]$. One must pay great heed to signs of invasion and metastasis during histopathological observations, i.e. invasion into blood vessels, lymphatic vessels and nerves, as well as the circumferential resection margin. The tumor bud is associated with invasion and should be described [15-18]. The number of lymph glands detected must be $\geq 12[18,19]$.

5. CRC has three grades that can be identified in combination with morphological and molecular properties.

Undifferentiated carcinoma, which belonged to the fourth level in the previous classification, denotes a tumor with epithelioid morphology but without duct formation, mucus production, or squamous differentiation, neuroendocrine differentiation or sarcomatoid differentiation, some of which have a high frequency of microsatellite instability and belong to a low level [13] (online suppl. appendix 1; for all online suppl. material, see www. karger.com/doi/10.1159/000362585).

6. If qualified, analyses of a relevant indicator of tumor proliferation or relevant proteins as well as microsatellite instability screening can be taken into account as alternatives.

Relevant indicators of tumor proliferation include Ki67, p53, p2 $1^{\text {ras }}$, the epidermal growth factor receptor, BRAF and phosphatase and tensin homolog (PTEN). Relevant proteins include the immunohistochemical detection of MLH1, MSH2, MSH6 and PMS2. In CRC targeted therapy, the K-ras mutation should be detected in the application of anti-epidermal growth factor receptor monoclonal antibody $[13,19]$.

7. CRC is classified according to the tumor/regional lymph node/distant metastasis (TNM) staging system of CRC (seventh version, 2009) of the American Joint Committee on Cancer/International Union Against Cancer (AJCC)/UICC) (online suppl. appendix 2).

Primary tumor (T): $\mathrm{T}_{\mathrm{x}}=$ Primary tumor cannot be evaluated; $\mathrm{T}_{0}=$ no evidence of primary tumor; $\mathrm{T}_{\text {is }}=$ carcinoma in situ, confined to the epithelium or invades to the lamina propria; $\mathrm{T}_{1}=$ tumor invades to the submucosa; $\mathrm{T}_{2}=$ tumor invades to the muscularis propria; $\mathrm{T}_{3}=$ tumor penetrates the muscularis propria and reaches the subserosa, or invades the adjacent colorectal tissues without peritoneal covering; $\mathrm{T}_{4}=$ tumor penetrates the visceral peritoneum, or directly invades or adheres to other organs or structures, where $\mathrm{T}_{4 \mathrm{a}}=$ tumor penetrates the visceral peritoneum and $\mathrm{T}_{4 \mathrm{~b}}=$ tumor directly invades or adheres to other organs or structures.

Regional lymph nodes ( $N$ ): $\mathrm{N}_{\mathrm{x}}=$ Regional lymph nodes cannot be evaluated; $\mathrm{N}_{0}=$ has no regional lymphatic metastasis; $\mathrm{N}_{1}=$ has $1-3$ regions with lymphatic metastasis, where $\mathrm{N}_{1 \mathrm{a}}=$ has one region, $\mathrm{N}_{1 \mathrm{~b}}=$ has $2-3$ regions, and $\mathrm{N}_{1 \mathrm{c}}=$ has tumor satellite nodules in the subserosa, mesentery, colon/perirectal or the soft tissues around without regional lymphatic metastasis; $\mathrm{N}_{2}=$ over 4 regions with lymphatic metastasis, where $\mathrm{N}_{2 \mathrm{a}}=$ has 4-6 regions and $\mathrm{N}_{2 \mathrm{~b}}=$ has seven or more regions.

Distant metastasis (M): $\mathrm{M}_{0}=$ Has no distant metastasis; $\mathrm{M}_{1}=$ has distant metastasis, where $\mathrm{M}_{1 \mathrm{a}}=$ has distant metastasis limited to one organ, and $\mathrm{M}_{1 \mathrm{~b}}=$ has over one organ/site or the peritoneum. 
8. Colorectal polyps are divided into neoplastic and non-neoplastic types; the former are called adenomas and classified into IEN.

Non-neoplastic polyps can be hyperplastic polyps, hamartomatous polyps (including juvenile polyposis and melanin spots-gastrointestinal multiple polyps syndrome, i.e., PeutzJeghers polyps or Peutz-Jeghers syndrome), inflammatory polyps, lymphoid polyps and mucosal prolapse polyps.

Adenomas can be early adenoma (abnormal crypt foci), traditional adenoma (including tubular adenoma, villous adenoma and tubular villous adenoma), serrated adenomas (including traditional serrated adenoma, wide-based serrated adenoma polyps and mixed hyperplastic polyp/serrated adenoma) and clubbing-micro duct adenoma.

Intestinal polyposis is a disease in which there are $>100$ intestinal polyps $[20,21]$. These can include familial adenomatous polyposis (FAP), serrated polyposis, Peutz-Jeghers syndrome, juvenile polyposis syndrome, Cowden syndrome, Cronkhite-Canada syndrome, inflammatory polyposis and lymphoid polyposis.

9. IEN is an epithelial lesion with morphological changes (including structural and cellular morphological changes) along with abnormal kinetics of proliferation and cellular differentiation.

This terminology was recorded in the 2000 edition of the WHO document and introduced to describe the preinvasive lesions of the large intestine, which have cloning changes that tend to be associated with invasive diseases $[13,22]$. In essence, IEN should be synonymous with the previous epithelial dysplasia, which may be divided into low- and high-grade cervical IEN (CIN) according to the degree of severity.

Low-grade IEN corresponds to grade I-II epithelial dysplasia. High-grade IEN is a mucosal lesion with malignant features in the structure and cell morphology of tissues but lacks invasion of the mesenchyme, including severe (grade III) interstitial dysplasia and carcinoma in situ. Whether or not IEN is present, the specimen should be completely resected to determine the depth of invasion. High-grade IEN cannot be an excuse for diagnostic mistakes and should always be confirmed.

\section{Screening for Colorectal Tumors}

\section{(I) Strategy and Method for Screening Objects}

10. The recommended target population for the screening for colorectal tumors is $50-74$ years old.

The incidence of colorectal tumors increases significantly after the age of 50 years, is highest for those aged 75-80 years and then gradually decreases. Studies from outside China suggest that those aged 76-85 years should not be included in CRC screening [23]. Therefore, the highest age of screening for CRC in China has been determined to be 74 years.

11. Due to its large population and the rising incidence of CRC in China, preliminary screening should be undertaken to find persons at high risk, followed by colonoscopy.

China has a large population, so if all individuals of a certain age need colonoscopy, the number would be huge and a great challenge to healthcare systems. A person at high risk is identified during preliminary screening and then receives additional colonoscopy. Hence, considerable manpower and material resources can be saved. 
12. Screening methods include FOBT, a questionnaire on high-risk factors, colonoscopy and sigmoidoscopy.

FOBT is one of the most widely used screening methods with a diagnostic sensitivity of $35.6-79.4 \%[24,25]$. The common reagents are guaiac, benzidine and quantitative assay antibodies. Immunoassay FOBTs are superior to those with chemical reagents [26]. At least two detection tests or application of the sequential fecal occult blood test are recommended (online suppl. appendix 3).

The questionnaire on high-risk factors is a simple and cost-effective screening method (online suppl. appendix 4) which can be used to find colorectal precancerous lesions based on epidemic case-control studies [27].

Digital rectal examination can help locate neoplasms in the inferior rectal segment, which is recommended in high-risk populations who have not undergone colonoscopy. Colonoscopy is essential for the diagnosis of CRC and should be carried out if necessary. The rate of detection of tumors can be influenced by endoscopy, the skills of the examiners and the time spent examining the patient [28].

Although sigmoidoscopy can only be used to monitor the gut beyond the splenic flexure, it may reduce the overall mortality of CRC populations [29]. Therefore, sigmoidoscopy is recommended if colonoscopy cannot be carried out.

\section{A screening cycle of 3 years is recommended for persistent interventions.}

Compared with the cumulative mortality of non-screening control regions, that of colorectal tumor screening regions using preliminary screening followed by colonoscopy can be reduced by the third year, reaches the lowest point at the fourth year and then increases gradually to the sixth year, whereas there are no significant differences in mortality between the two regions. Therefore, a 3-year screening interval is appropriate for reducing the mortality of CRC in screening regions [30].

14. Fecal DNA detection and computed tomography simulation colonoscopy can be used only for research and are not suitable for population screening.

Fecal DNA detection is the detection of DNA mutations and/or methylation in the stool samples for the diagnosis of CRC. Computed tomography simulation colonoscopy is used to simulate three-dimensional imaging of the colon with the abdomen after gut cleansing to aid the diagnosis of intestinal tumors. The methods described above are relatively complex and expensive, with the risk of false-positive results or radiation hazards. As such, they are not recommended for current CRC screening [4] but can help in the early diagnosis.

15. Preliminary screening followed by colonoscopy in the early diagnosis and treatment of $C R C$ can be used as a reference for the screening for colorectal tumors.

The objective population for preliminary screening followed by colonoscopy is aged 50-74 years and needs a questionnaire related to high-risk factors (online suppl. appendix 4) $[31,32]$ and at least two FOBT immunoassays. Populations at a high risk of CRC are those meeting any one of the following items: (i) positive FOBT; (ii) first-degree relatives with the a history of CRC; (iii) history of intestinal adenomas; (iv) history of cancer; (v) meeting any two of the following six items: chronic diarrhea, chronic constipation, bloody mucus, chronic appendicitis or appendectomy, chronic cholecystitis or cholecystectomy, or long-term mental depression. Colonoscopy should be undertaken for populations carrying a high risk of CRC. The biopsy and pathological diagnosis should be carried out for all polypoid lesions. Patients with adenomas, CRC or other lesions associated with high-grade IEN should be treated promptly. 


\section{(II) Opportunistic Screening}

16. Opportunistic screening (also known as 'individual screening' or 'case-finding') is when subjects can seek medical attention or the physician decides the screening methods and strategies based on the danger level of the disease [33].

Opportunistic screening is clinical-based screening that can be carried out in hospitals, community clinics and town hospitals. Screening methods (direct colonoscopy or positive FOBT + colonoscopy) are chosen based on the characteristics of the individual. These can include healthy subjects actively having physical examinations, patients looking for treatment for other diseases but carrying high-risk factors for CRC, and outpatients without the symptoms associated with colorectal tumors. Such screening is focused on the early detection of colorectal tumors (including precancerous lesions) and improvement of therapeutic effects, but cannot be used to determine whether the incidence of CRC in a certain population or region can be reduced.

Mass screening (also known as 'natural population screening' or 'asymptomatic population screening') is screening based on the population through a standardized method and is usually launched by the relevant departments or organizations. The overall population (community or units) meeting the screening criteria is urged to take part in the screening in a specified and relatively short time by various means. The purpose is not only to detect early cancer and improve the therapeutic effect, but also to locate precancerous disease and reduce the incidence with appropriate interventions to prevent CRC.

17. The opportunistic screening for colorectal tumors may improve prognosis and quality of life (QoL) and reduce the huge healthcare burden of the state, and is a screening mode suitable for the current healthcare system and national situation [34, 35].

Due to the large population of China, the annual national expenditure for CRC screening is about RMB 18.081 billion. This sum is for the lowest-cost FOBT and screening for people $>60$ years of age. According to the requirements of 'Guidelines for the Screening and Early Diagnosis and Treatment of Major Cancers in China' formulated by the China Cancer Foundation, the population aged $>40$ years should receive CRC screening. However, such screening necessitates funding that is far beyond that available by national financial and medical insurance. In addition, CRC screening is part-time work for clinical staff, but national screening will demand many full-time medical staff and specialized medical facilities, which cannot be met under current national health and human resources.

Opportunistic screening as a type of screening mode for colorectal tumors based on clinics can be carried out in hospitals, community clinics and medical centers due to its simplicity and practicality. Special funding and additional staff are not needed, but patient compliance is. Hence, it is eminently feasible [35-42].

18. Evidence-based research has confirmed that FOBT can be used for the screening for colorectal tumors and that colonoscopy is an intensive detection.

Studies on the screening and early diagnosis of CRC began in the 1970s in China. Li and colleagues [43-46] designed the 'Sequential FOBT Screening Program' in 1988 and demonstrated it in several large-scale population screenings. Zheng and colleagues [47-49] confirmed the high-risk factors of CRC in China based on research in regions with a high occurrence of CRC, Jiashan and Haining as well as Zhejiang, and created the 'Quantitative Questionnaire of High-Risk Factors for CRC Screening' (online suppl. appendix 4).

19. Opportunistic screening for colorectal tumors involves (i) ensuring that the community, hospital outpatient and health examination centers can implement preliminary screening, 
(ii) knowing that the screening methods and strategies may differ between individuals, and

(iii) ensuring that it can be divided into screening and intensive detection.

There are two screening methods: (i) immunoassay FOBT and (ii) questionnaires (online suppl. appendix 4, 'Quantitative Questionnaire of High-Risk Factors for CRC Screening'). The objects of screening are patients and healthy individuals seeking a physical examination. The object of intensive investigation involves a positive FOBT and individuals at high risk as determined by questionnaire. The intensive method is colonoscopy.

20. The screening objects are divided into 'general' individuals and 'high-risk' individuals in accordance with the risk of CRC (for which different screening strategies are made). All patients undergoing intensive detection need to be registered and filed, and regular follow-up should be arranged according to the specific terms described in online supplementary appendix 5.

(i) General individuals: FOBT (immunochemical method) can be carried out on outpatients and healthy active people having physical examinations; those with a positive response are suggested to have additional colonoscopy. (ii) High-risk individuals: they are the focus of screening and their screening does not have to be bound by FOBT results (immunoassay or chemical method). For this group, colonoscopy is recommended, and tumor marker detection and/or genetic test is carried out if necessary.

For opportunistic screening, the definition of a high-risk individual is someone having one of the following items: (i) gastrointestinal symptoms such as blood/mucus in stools, abdominal pain, and unexplained anemia/weight loss; (ii) history of CRC; (iii) history of colorectal precancerous diseases (e.g. CRAs, ulcerative colitis, Crohn's disease, schistosomiasis); (iv) immediate family members with a history of CRC; (v) immediate family members with a history of colorectal polyps; (vi) history of pelvic radiotherapy.

\section{(III) Screening and Monitoring of Familial Colorectal Tumors}

21. Screening strategies for hereditary non-polyposis CRC (HNPCC): screening objects are patients meeting the diagnostic criteria for HNPCC and having family members with HNPCC. Screening is referenced to mutations of the pathogenic gene in the family.

(i) Families in which a pathogenic mutant gene has been detected: the screening objects need mutation analyses of the related genes. For those members without mutation analyses, colonoscopy is needed once every 1-2 years beginning at the age of 20-25 years, or 10 years earlier than the minimum age of onset in the family (the earliest one), and once a year after the age of 35 years [50,51]. Screening of non-mutation gene carriers can be referenced to that of the average risk of the CRC population. (ii) Families with uncertain pathogenic mutant genes: the screening objects need an immunohistochemical assay and microsatellite instability detection: (a) if both negative, the screening depends on individual circumstances and assessment of family risk; (b) at least one positive (deletion of protein expression as judged by immunohistochemical staining and/or high-degree microsatellite instability), MLH1 and MSH2, or as well as MSH6 and PMS2 genes can also be added to the mutation analyses. If patients with a pathogenic mutation gene or mutation gene carriers are found, or if gene mutation analyses have not been done, the screening can be referenced to item (i) above. If patients with a pathogenic mutant gene are not found, it is recommended that the screening of patients and their first-degree relatives be referenced to that of pathogenic mutation carriers in item (i) above (to avoid missing the diagnosis caused by technical issues), and the screening of other family members depends on individual circumstances and risk assessment for the family. 
22. In the screening of patients with APC gene-associated polyposis (including classical FAP, mild FAP, Gardner syndrome and Turcot syndrome), probands (the first to be found) should be diagnosed first followed by predictive screening.

(i) Confirmation of probands: (a) if the patient meets the diagnostic criteria for FAP or is suspected to have APC gene-associated polyposis, APC gene sequencing analyses and multiplex ligation-dependent probe amplification analyses should be done; (b) if no APC gene mutation is found, MYH gene molecular genetic testing is needed. (ii) Predictive screening: asymptomatic family members are at risk, so whether they have the familial mutant gene should be confirmed as soon as possible. If the inherited pathogenic APC gene mutation is not found by molecular genetic testing (even with diagnosed family members), CRC screening should be referenced to that of the average-risk population beginning at the age of 50 years. If the APC gene mutation testing is negative but with one or more diagnosed relatives not belonging to the same generation, linkage analyses should be considered with reference to the monitoring methods in item (iii) below and according to individual circumstances and familial risk. (iii) The monitoring methods for patients with APC gene-associated polyposis, pathogenic APC gene mutation carriers without symptoms, and family members who have not had molecular genetic testing: (a) sigmoidoscopy or colonoscopy is needed once every 1-2 years beginning at the age of 10-12 years and, if polyps are found, colonoscopy should be done once a year until colectomy; (b) upper gastrointestinal endoscopy is needed after the age of 25 years or before colectomy, and reviewed once every 1-3 years; (c) examination (endoscopic or radiographic) of the small intestine is necessary once every 1-3 years if a duodenal adenoma is found or before colectomy.

23. Screening for Peutz-Jeghers syndrome includes confirmation of probands and prospective screening.

(i) Confirmation of probands: it is recommended that all carriers of Peutz-Jeghers syndrome polyps or patients with typical pigmentation of the oral mucosa should have molecular genetic testing [52]. (ii) Prospective screening: molecular genetic testing is necessary for asymptomatic adults with a family history. (iii) Monitoring methods: (a) stomach: upper gastrointestinal endoscopy is needed once every 2-3 years beginning at the age of 8 years; (b) small intestine: endoscopic or radiographic examination is needed once every 2-3 years from the age of 8 years; (c) large intestine: colonoscopy is needed once every 2-3 years from the age of 18 years.

24. Monitoring of juvenile polyposis syndrome needs to be carried out aimed at different parts [53].

Colon: colonoscopy is needed starting before the age of 15 years once a year if polyps are found, and once every 2-3 years if polyps are not found. Stomach: upper gastrointestinal endoscopy is needed starting before the age of 15 years once a year if polyps are found, and once every 2-3 years if polyps are not found.

25. 'Other familial CRC' is defined as CRC or CRA patients having family members (one or more first-degree relatives, or two or more second-degree relatives) suffering from CRC or relevant tumors but who do not conform to any clinical diagnostic criteria for hereditary CRC. Screening depends on the age of onset [53].

(i) Having CRC patients as first-degree relatives at age 50-60 years: colonoscopy is needed once every 3 years from the age of 40 years. (ii) Having one CRC patient as a firstdegree relative aged $<50$ years, or two or more patients at whatever age: colonoscopy is needed from the age of 40 years or 10 years earlier than the youngest patient, and once every 3-5 years according to family history. (iii) Having one CRC patient as a first-degree relative 
aged $>60$ years, or two or more secondary relatives at whatever age: colonoscopy is needed once every 5 years from the age of 50 years.

\section{(IV) Tumor Screening Associated with Inflammatory Bowel Diseases}

26. Inflammatory bowel diseases are high-risk factors for CRC, among which the high-risk factors of ulcerative colitis carcinogenesis include colonic lesions and a course of $>10$ years. Much more attention should be paid to the colonoscopy screening of such patients.

Colonic lesions and repeated long-term inflammation are the major high-risk factors for the carcinogenesis of ulcerative colitis. In general, the prevalence of cancer is comparatively low for simple ulcerative colitis of the rectum and left colon. Studies have shown that the prevalence of cancer is $2 \%$ for ulcerative colitis lasting $>10$ years, $8 \%$ for $>20$ years and $18 \%$ for $>30$ years [54]; the prevalence is very low for $<10$ years. Other high-risk factors include sclerosing cholangitis, young patients and a family history of cancer $[55,56]$.

Based on the high-risk factors of ulcerative colitis, more attention should be paid to the colonoscopy screening of such patients, including colonoscopy screening of the entire colon for patients with a 10-year duration of ulcerative colitis and colonoscopy screening of the left colon for those with a 15-20-year duration of ulcerative colitis [57-59]. The largest screening studies have shown that 5 -year screening can lead to benefits in $\leq 73 \%$ of subjects, yet to benefits in only $36 \%$ in the group of those who were not screened [60]. This result suggests that targeted screening helps reduce the incidence of cancerous ulcerative colitis. Nevertheless, implementation of a cancer screening program for ulcerative colitis has not been carried out extensively [61].

27. The interval of colonoscopy screening is determined based on the classification of the degree of risk of ulcerative colitis carcinogenesis.

In reference to the 2011 European guidelines [57], the risk of CRC related to ulcerative colitis is divided into three degrees: (i) low-degree risk refers to colonic lesions stabilized or confined to the left colon; (ii) moderate-degree risk refers to colonic lesions confirmed with mild active inflammatory changes by endoscopy, polyps which have formed after inflammation, or CRC patients with first-degree relatives who had disease onset at age $>50$ years; (iii) high-degree risk refers to colonic lesions confirmed to have moderate-to-severe active inflammatory changes by endoscopy, accompanied by a history of primary sclerosing cholangitis, colonic stenosis or any degree of IEN (dysplasia) during the previous 5 years, and CRC patients having first-degree relatives who had the disease before the age of 50 years. The interval of colonoscopy screening varies with different risks: once every 5 years for low-risk populations, once every 3 years for moderate-risk populations, and annually for high-risk populations. If colonoscopy does not reach the cecum, it should be repeated.

28. The main purpose of colonoscopy screening in patients with ulcerative colitis is to detect mucosal IEN (dysplasia) and its related lesions as early as possible. To this end, multi-point biopsy can be done to improve detection or chromoendoscopy and magnifying endoscopy technology can be adopted.

In general, the intestinal mucosal lesions in ulcerative colitis are flat lesions or hypertrophic polypoid lesions, including dysplasia-associated lesion or mass. With regard to histology they can be (i) adenomatous lesions, (ii) serrated lesions or (iii) villous high-mucussecreting lesions. At the advanced stage, stenotic lesions may result [62]. Finding flat lesions by endoscopy is very difficult. 
29. The canceration rate of Crohn's disease is similar to that of ulcerative colitis, including CRC and small bowel tumors. Long-term active disease is a high-risk factor for cancer. The screening for Crohn's disease invading the colorectum is similar to that for ulcerative colitis.

Ulcerative colitis and Crohn's disease can lead to CRC. However, the rate of canceration of Crohn's disease is low [63]. Single-center studies in China have not reported any cancerous cases of Crohn's disease. Lesions invading the colorectum can promote canceration, which is also one of the high-risk factors for tumors of the small intestine. Screening for the invasion of Crohn's disease into the colorectum is similar to that of ulcerative colitis (see the corresponding items above) [64].

\section{Early Diagnosis of Colorectal Tumors}

\section{(I) Laboratory Diagnosis}

30. The serological diagnosis of colorectal tumors is hampered by a lack of sensitive and specific methods.

Conventional serological detection of tumor antigen markers, such as carcinoembryonic antigen, cancer antigen 125 and cancer antigen 19-9, is easy to carry out, but the sensitivity and specificity needs to be improved. Detection of new indicators such as peripheral blood telomerase activity [65], mRNA of human telomerase reverse transcriptase [66] and some miRNAs, is much more complex, and their clinical value needs further evaluation.

31. A positive result of FOBT suggests only that further examination is needed for the diagnosis. Detection of fecal DNA and transferrin has limited importance for the diagnosis of colorectal tumors, but contributes to their screening.

DNA can be extracted directly from feces. Detection of the mutations of the K-ras gene [67-69], the p53 gene [70] and the APC gene [71] may aid the early diagnosis of CRC. The detection of DNA in feces has advantages such as convenience and good compliance from patients, but large-scale population-control studies are lacking. The sensitivity and specificity needs to be improved further.

Transferrin is the major iron-containing protein in plasma. It is responsible for the transport of iron absorbed from the digestive tract and released by the degradation of erythrocytes. Transferrin is present at very low levels in the feces of healthy people, but is very high if gastrointestinal bleeding is present. The ratio of hemoglobin to transferrin is 51.2/1 in the blood and 5.4/1 in the feces. Studies have shown that the sensitivity of detection of transferrin in feces is higher than that of FOBT immunoassay for the detection of CRAs and that it can be complementary with FOBT [72].

\section{(II) Imaging Diagnosis}

32. Air-barium double-contrast radiography can be used as an adjunct examination for colorectal tumors, but the diagnostic value is less than that of endoscopy.

Under air-barium double-contrast radiography, CRC shows destruction of mucosal folds, filling defects, niche shadows, stenosis, wall stiffness, loss of peristalsis as well as oppression/ displacement of surrounding organs. Few tumors can be found with high-quality air-barium double-contrast radiography. The rate of detection of flat or prominent lesions (IIa type) is $\leq 70 \%$, but that of small lesions in the bending segments and the anterior and posterior walls of the large intestine is low. 
33. Computed tomography colonoscopy is non-invasive and has unique advantages for patients who cannot tolerate colonoscopy, but has limited value for early diagnosis.

Computed tomography colonoscopy can display colorectal lesions at multiple directions, angles and levels. It can accurately determine the circumference and thickness of the bowel and show the range of invasion of the tumor and surrounding bowel. Intraluminal reconstruction images can clearly show the intestinal mucosal folds for the early detection of colorectal lesions. However, computed tomography colonoscopy cannot biopsy the lesions, has false-negative results for small or flat lesions and false-positive results due to feces [73, 74].

\section{(III) Endoscopic Diagnosis}

34. Colonoscopy combined with pathological examination is the standard method for the diagnosis of colorectal tumors. Adequate bowel preparation and careful observation when withdrawn can improve the rate of detection of colorectal tumors [75-79].

The size, shape and location of the adenoma, the patient's age and the number of adenomas under initial colonoscopy are risk factors for a missed diagnosis in colonoscopy [78]. Studies have shown that patients with a tumor size $<10 \mathrm{~mm}$, a flat tumor, tumor in the left colon, age $>60$ years or $>2$ tumors at initial colonoscopy would be missed. Therefore, the diagnosis of small flat lesions should be emphasized and strengthened, especially for lesions in the left colon.

35. Early CRC has two types under endoscopy: prominent and flat [80]. Biopsy is not recommended for the flat type under endoscopy.

The prominent type (type I) is a lesion that protrudes significantly in the intestine with a base diameter that is significantly smaller than the maximum diameter of lesions (pedunculated or subpedunculated), or a hemispherical lesion with a base diameter significantly greater than the head diameter. According to the base and pedicle of the lesion, this type is divided into three subtypes: (i) pedunculated, the lesion base has obvious pedicles connected with the intestinal wall; (ii) subpedunculated, the lesion base has subpedicles connected with the intestinal wall; (iii) superficial, the lesion significantly protrudes in the mucosal surface without an obvious pedicle structure in the lesion base, whose diameter is less or greater than the maximum diameter of the head.

The flat type (type II) has a carpet-like shape similar to that of the mucosal surface, slightly prominent or depressed on the mucosal surface, with a base diameter close or equal to the maximum diameter of the surface. This type is divided into four subtypes: (i) IIa, a prominent surface; (ii) IIb, a flat surface; (iii) IIc, a depressed surface; (iv) a laterally spreading tumor whose maximum diameter is $>10 \mathrm{~mm}$. For flat lesions, a biopsy at a single location cannot reflect the overall situation of the lesions. Instead it can cause inflammation of the mucous layer and submucosa as well as adhesion with the muscularis propria, resulting in a difficult endoscopic resection.

36. The colonic mucosal staining method has been shown to significantly improve the rate of detection of small lesions (especially flat lesions) and more clearly shows the boundary and surface structure of the lesions for the initial assessment of the lesions [81-83].

The content of the endoscopy (colonoscopy) diagnosis is drafted based on the consensus regarding the endoscopic diagnosis and treatment of early CRC by the Endoscopy Professional Committee of the Colorectal Study Group of the Chinese Medical Association in 2008 [84]. A common colorant is $0.2-0.4 \%$ indigo carmine solution, which is bright blue and not 
absorbed by the mucous membrane. After spraying and staining, it can depositin the depressed fine structures of the mucosal surface with good contrast to enable observation of the fine structures on the lesion surface and the border of the flat lesions, especially to improve the rate of diagnosis of colorectal flat lesions. Other studies have shown that acetate staining followed by indigo carmine staining can improve the accuracy of the pit pattern analysis [85].

37. Magnifying chromoendoscopy with pit patterns can help determine the nature of the lesions and the depth of the invasion. It can also make the diagnosis consistent with the pathological results to determine the feasibility of endoscopic treatment [86-88].

The Kudo classification from 1996 has been adopted widely to classify colonic mucosal crypts. According to the shape and size of the crypt, it is divided into five types, I-V, where type III is divided into IIIs and IIIL (the characteristics of different types are shown in online suppl. appendix 6).

38. The vascular classification under NBI can be used to identify intestinal neoplastic and non-neoplastic lesions with high sensitivity and specificity for the appropriate choice of treatments [89-91]. Endoscopic ultrasound can be used to determine the depth of invasion of CRC with higher accuracy for the T stage and determine the suitability of endoscopic therapy [92].

Narrow-band images emphasize the vascular network (CP) and the surface structure of the mucosal surface. The blood vessels on the colonic mucosal surface are brown and the deep veins are green under NBI. The currently common NBI typing has Sano typing [89] and Showa typing [90]. The former, which is simple and practical, is divided into three types: type I the structure of the mucosal surface is regular and honeycomb-like and CP is not visible; type II - the mucosal surface structure is honeycomb-like, round, and regular, and CP with a uniform diameter can be seen; type III - the blood vessels around the pit are irregular, with interrupted branches and different diameters (online suppl. appendix 7). Sano typing can be used to determine the lesions of colorectal tumors with a sensitivity and specificity of $>90 \%$, which is believed to be better than that for chromoendoscopy [89].

In addition, endoscopic techniques such as I-Scan Intelligent Optical Staining ${ }^{\circledR}$ [93-95] and confocal laser endomicroscopy [96] have higher accuracy for the identification of intestinal neoplastic and non-neoplastic lesions, whereas determination of the invasion depth needs to be validated further.

\section{Endoscopic Treatment of Early CRC and Precancerous Lesions}

39. The indications for endoscopic treatment of early CRC are (i) invasion depth limited to cancers in the mucosal layer and (ii) invasion depth limited to cancers in the submucosal layer (sml) [97].

Mucosal cancer is the absolute indication for endoscopic treatment not due to lymphatic and vascular metastasis. The prevalence of lymphatic metastasis of sml is only $3.2 \%$, which can be used as a relative indication. However, the resected specimen should be strictly assessed to determine whether lymphatic or vascular invasion is present and whether additional surgery is needed.

40. Some systemic diseases or pregnancy are contraindications for endoscopic treatment for early CRC.

In this situation, contraindications can be patients (i) with severe heart and lung disease who cannot tolerate endoscopy, (ii) with coagulation disorders, (iii) with unstable vital signs, (iv) with spiritual beliefs or consciousness disorders who cannot cooperate with treatment, 
(v) suspected or clearly having intestinal perforation, intestinal necrosis or severe peritonitis, or (vi) with toxic megacolon or fulminating colitis [98].

41. The current endoscopic treatments [97, 99-102] for early CRC include high-frequency electric snare polypectomy, hot biopsy forceps surgery, endoscopic mucosal resection, endoscopic piecemeal mucosal resection and endoscopic submucosal dissection.

These treatments should be carried out according to the lesions, technology and hard ware conditions of each unit.

42. For resected specimens under endoscopy, the pathologist should assess whether the tumor invades into the base and surrounding cutting edge and whether lymphatic or vascular invasion is present, and determine whether additional surgery is required according to the pathology results.

The resected specimens under endoscopy should be spread out and fixed with pins, the lesion sizes measured and parallel continuous slices made with 2-mm intervals. The pathologist should assess whether the tumor invades into the base and surrounding cutting edge and whether lymphatic or vascular invasion is present, and determine whether additional surgery is required according to the pathology results [102].

\section{Monitoring and Follow-Up after Endoscopic Treatment of Colorectal Tumors}

43. CRA removal under endoscopy (especially advanced adenoma) can prevent CRC to some extent, but CRA has an obvious recurrence trend.

Previously, scholars believed that CRA removal and follow-up under endoscopy could reduce CRC occurrence by $>75 \%$ [3], which has not been found in recent studies. Martinez et al. [103] surveyed 9,167 patients who underwent CRA resection and found that, with an average follow-up of 4 years, $46.7 \%$ had CRA recurrence, $11.2 \%$ had advanced adenoma, and in $0.6 \%$ CRA developed to CRC. The recurrence was $\leq 40-50 \%$ after CRA removal for 3 years [104]. According to the studies of five medical centers in China, the 1-year recurrence after removal of advanced adenoma was $\leq 59.46 \%$ and that for 5 years was $78.07 \%$ [105].

44. The occurrence and diagnosis of interval CRC should be emphasized during screening and follow-up.

An 'interval cancer' is a cancer diagnosed between screening and post-screening monitoring [106]. The incidence of interval CRC is $0.3-0.9 \%$ due to the fast growth of new tumors [107], incomplete removal of a previous adenoma [108] or a missed diagnosis in the last check (usually the prevalence of a missed diagnosis for adenomas $>1 \mathrm{~cm}$ in diameter is $2-12 \%)$.

45. The follow-up interval after the removal or surgery of colorectal tumors should be different with lesions: (i) the patient with an advanced adenoma should receive colonoscopy for 3-6 months; (ii) CRC should receive colonoscopy within 1 year after surgery and patients with polyps should receive colonoscopy for 1-3 years (online suppl. appendix 8); (iii) adenomatous polyposis receiving anus preservation surgery should receive colonoscopy every 12 months focusing on examination of the rectal stump.

The researchers, headed by Prof. Winawer at the Memorial Sloan-Kettering Cancer Center (New York, N.Y., USA), proposed, in 2006, how to follow-up and monitor after CRA removal. They stated that a high-risk patient (diameter $>1 \mathrm{~cm} /$ high-grade IEN/ $\geq 3$ polyps/ villous structure) should receive colonoscopy after 3 years; a low-risk patient should receive 
colonoscopy after 5-10 years; a patient with hyperplastic polyps should receive colonoscopy after 10 years; a patient with $>10$ polyps in one check should receive colonoscopy within 3 years according to the clinical situation; a patient with sessile flat polyps should be reviewed after 2-6 months to identify complete removal $[4,109]$. According to the recurrence after CRA removal in reports in China and abroad, the follow-up interval after CRA removal in China can refer to the criteria mentioned above with some amendments. If a tumor is not found at the second inspection, the subsequent colonoscopy may be postponed.

46. After endoscopic treatment of early CRC, follow-up colonoscopy should be done at 3, 6 and 12 months. Subjects without residue or recurrence can receive one follow-up each year, those with residue or recurrence can receive additional resection, one follow-up every 3 months (including detection of serum tumor markers and FOBT), and one colonoscopy every year after complete removal.

Early CRC or precancerous lesions receive graded resection and can recur and remain, most of which occurs within 12 months.

\section{Chemoprevention of Colorectal Tumors}

47. CRA removal under endoscopy cannot prevent its recurrence [110].

As mentioned above, CRA removal under endoscopy is associated with a higher prevalence of recurrence. Simultaneously, some studies reported that CRA removal was beneficial for the prevention of CRC in the left distal end but not for the right proximal end (and that the latter has more rapid growth [111]), and that more flat polyps which are difficult to identify under colonoscopy can also be malignant [112]. These scholars considered that removal of a right CRA was less beneficial than that of a left CRA.

48. $C R C$ chemoprevention (primary prevention of CRC) contains the primary and secondary prevention for CRA. Primary prevention for CRA is to reduce the incidence of CRA. Secondary prevention for CRA should be aimed at recurrent lesions after adenoma removal under endoscopy [113-115].

Relying entirely on CRA removal under endoscopy to prevent CRC is not sensible due to poor medical conditions in rural areas, poor compliance from the patient, difficult spread of the application, high prevalence of recurrence after removal and difficulty in the identification of some flat polyps. Sporn and colleagues were the first to propose drug-based chemoprevention [116, 117]. These scholars considered prevention of CRA recurrence to be the ultimate goal of CRC chemoprevention.

49. Primary prevention of adenomas includes (i) improved diet with more fiber [118, 119], (ii) supplements containing calcium and vitamin D [120-122], (iii) supplements containing folic acid for those with lower plasma folate concentrations [123,124], and (iv) cessation of tobacco smoking [6].

Some prospective clinical trials have shown that high-fiber foods have a preventive effect. However, two randomized controlled clinical trials $[125,126]$ classified $>1,000$ cases with CRA and polyp removal into two groups: a low-fat and high-fiber diet group and a low-fiber diet group. No obvious difference in adenoma recurrence between the two groups was found at 3-year and 5-year follow-up, which showed that high-fiber foods were not associated with CRC prevention. However, recent studies with much larger sample sizes showed that a highfiber diet was negatively correlated with CRC occurrence. The scientists involved were from several European and American medical centers; 33,971 cases (3,591 cases with adenomas) 
and 519,978 patients were involved, respectively, and the decrease in CRC risk by consuming a high-fiber diet was $27 \%$ and $40 \%$, respectively $[118,119]$.

Epidemiological surveys have shown that bioactive food compositions such as folic acid, cellulose, calcium and vitamin D as well as drugs have some CRC preventive features with very few side effects [120-122, 126, 127]. Bioactive food compositions for CRC chemoprevention include folic acid [123, 128]. Despite some controversy [129-131], it is generally believed that early application of folic acid can prevent adenoma, but prevention of recurrence of adenoma (or after adenoma removal) is not known [124,132].

Recently, the Asia-Pacific CRC Working Group investigated 91 cases with colorectal tumors and 24 cases with advanced adenomas in 395 asymptomatic smokers, and 76 cases with colorectal tumors and 15 patients with advanced adenomas in 452 non-smokers. It is thought that the risk for smokers with colorectal tumors is 1.5 times higher than that for nonsmokers, whereas the risk for smokers with advanced adenoma is 1.9 times higher [6].

50. Cases with a high risk of colorectal tumors (aged $>50$ years, male, with a family history of colorectal tumors or other cancers, smokers, overweight, history of gallbladder surgery or schistosomiasis) may receive non-steroidal anti-inflammatory drugs (NSAIDs) such as aspirin and selective cyclooxygenase-2 (Cox-2) inhibitors with a special attention to side effects [133-143].

Some observational studies have found that subjects who take aspirin regularly may reduce the occurrence of colorectal tumors. However, the results of randomized studies on aspirin are not consistent. A prospective study carried out by Chan et al. [134] at Massachusetts General Hospital not only confirmed the preventive effect of aspirin on CRC, but also discovered the administration period and dose of aspirin to minimize the risk of CRC: continuous administration for $\geq 6$ years at 14 tablets ( $325 \mathrm{mg} /$ tablet) per week. Therefore, the potential hazard of long-term usage at this dose needs to be considered carefully. Dubé et al. [135] considered the dose of aspirin to prevent CRC to be larger than that used to prevent cardiovascular disease ( $>10$ years) and that the side effects and expenditure-efficacy ratio should be considered carefully. In fact, the preventive effect of low-dose aspirin is controversial $[136,137]$.

It is widely acknowledged that Cox-2-specific inhibitors can prevent CRC. Cox-2 inhibitors can reduce the incidence of CRA in $72 \%$ of subjects. Celecoxib ( $400 \mathrm{mg}$ b.i.d.) was shown to reduce FAP adenomas in $30 \%$ of 81 patients, yet 100 mg reduced FAP adenomas in only $12 \%$. Hence, celecoxib has been approved by the US Food and Drug Administration (FDA) as a drug to prevent FAP [133].

However, non-selective NSAIDs and Cox-2 inhibitors have cardiovascular and gastrointestinal side effects or high costs [139-142]. After careful consideration, both agents are thought to be inappropriate for cases carrying a general risk of CRC [143].

51. NSAIDs and selective Cox-2 inhibitors have been recognized to prevent recurrence after adenoma removal. Supplementation with calcium and vitamin D [122], fiber diets and their intestinal metabolites short-chain fatty acids [144-147] may also aid prevention.

Epidemiological investigations and animal experiments have shown that calcium and vitamin D are related to the incidence of CRC or have preventive effects [120-122, 148, 149]. The preventive effects of calcium is achieved by binding secondary bile acids and fatty acids in the intestine and inhibiting the proliferation of intestinal epithelial cells. Vitamin D may be related to the induction of E-cadherin, inhibition of $\beta$-catenin, anti-proliferation and antimitosis. Clinical trials have shown that calcium supplementation can reduce CRA recurrence. Several studies showed that daily supplementation with calcium (>700 mg) can effectively prevent CRA recurrence. Calcium and vitamin D may be used together rather than singly to prevent CRC $[121,150]$. 
Many factors that can affect the biological activity of calcium and vitamin D in vivo should be considered. For example, vitamin D can promote the absorption and utilization of calcium, whereas the increased level of phosphorus may affect the bioavailability of calcium. Some ongoing large-scale clinical intervention trials can further evaluate the long-term safety and efficacy of single or combined usage of calcium and vitamin D.

Prevention of CRC or CRA by dietary fiber may be associated with short-chain fatty acids, especially butyrate $[144,145,151]$, which can protect the intestinal mucosa through various mechanisms [152] and can be used as an adjunct therapy for ulcerative colitis [153, 154]. Animal experiments have also clarified the preventive effects of butyrate [146, 147]. The healthcare products of butyrate may have certain preventive effects on colorectal tumors, but direct evidence from clinical trials is lacking.

\section{References}

$>1$ Cotton S, Sharp L, Little J: The adenoma-carcinoma sequence and prospects for the prevention of colorectal neoplasia. Crit Rev Oncog 1996;7:293-342.

$\checkmark 2$ Lieberman DA, Weiss DG, Bond JH, Ahnen DJ, Garewal H, Chejfec G: Use of colonoscopy to screen asymptomatic adults for colorectal cancer. Veterans Affairs Cooperative Study Group 380. N Engl J Med 2000;343:162-168.

-3 Winawer SJ, Zauber AG, Ho MN, O’Brien MJ, Gottlieb LS, Sternberg SS, Waye JD, Schapiro M, Bond JH, Panish JF, et al: Prevention of colorectal cancer by colonoscopic polypectomy. The National Polyp Study Workgroup. N Engl J Med 1993;329:1977-1981.

-4 Levin B, Lieberman DA, McFarland B, Andrews KS, Brooks D, Bond J, Dash C, Giardiello FM, Glick S, Johnson D, Johnson CD, Levin TR, Pickhardt PJ, Rex DK, Smith RA, Thorson A, Winawer SJ; American Cancer Society Colorectal Cancer Advisory Group; US Multi-Society Task Force; American College of Radiology Colon Cancer Committee: Screening and surveillance for the early detection of colorectal cancer and adenomatous polyps, 2008: a joint guideline from the American Cancer Society, the US Multi-Society Task Force on Colorectal Cancer, and the American College of Radiology. Gastroenterology 2008;134:1570-1595.

5 Sung JJ, Lau JY, Young GP, Sano Y, Chiu HM, Byeon JS, Yeoh KG, Goh KL, Sollano J, Rerknimitr R, Matsuda T, Wu KC, Ng S, Leung SY, Makharia G, Chong VH, Ho KY, Brooks D, Lieberman DA, Chan FK; Asia Pacific Working Group on Colorectal Cancer: Asia Pacific consensus recommendations for colorectal cancer screening. Gut 2008;57:1166-1176.

-6 Yeoh KG, Ho KY, Chiu HM, Zhu F, Ching JY, Wu DC, Matsuda T, Byeon JS, Lee SK, Goh KL, Sollano J, Rerknimitr R, Leong R, Tsoi K, Lin JT, Sung JJ: The Asia-Pacific Colorectal Screening score: a validated tool that stratifies risk for colorectal advanced neoplasia in asymptomatic Asian subjects. Gut 2011;60:1236-1241.

7 Zhao P, Chen WQ (eds): Chinese Cancer Registry Annual Report in 2010 (in Chinese). Beijing, Military Medical Science Press, 2011.

-8 Strul H, Kariv R, Leshno M, Halak A, Jakubowicz M, Santo M, Umansky M, Shirin H, Degani Y, Revivo M, Halpern $\mathrm{Z}$, Arber N: The prevalence rate and anatomic location of colorectal adenoma and cancer detected by colonoscopy in average-risk individuals aged 40-80 years. Am J Gastroenterol 2006;101:255-262.

-9 Lieberman DA, Prindiville S, Weiss DG, Willett W: Risk factors for advanced colonic neoplasia and hyperplastic polyps in asymptomatic individuals. JAMA 2003;290:2959-2967.

10 Imperiale TF, Glowinski EA, Lin-Cooper C, Larkin GN, Rogge JD, Ransohoff DF: Five-year risk of colorectal neoplasia after negative screening colonoscopy. N Engl J Med 2008;359:1218-1224.

11 Chen HM, Weng YR, Jiang B, Sheng JQ, Zheng P, Yu CG, Fang JY: Colonoscopy findings of colorectal adenoma and cancer in symptomatic patients in China between 1990 and 2009. J Dig Dis 2011;12:371-378.

12 Rundle AG, Lebwohl B, Vogel R, Levine S, Neugut AI: Colonoscopic screening in average-risk individuals ages 40-49 versus 50-59 years. Gastroenterology 2008;134:1311-1315.

13 Hamilton SR, Rubio CA, Vogelstein B, et al: Tumors of the colon and rectum: carcinoma of the colon and rectum; in Hamilton SR, Aaltonen LA (eds): World Health Organization Classification of Tumours: Pathology and Genetics of Tumours of the Digestive System, ed 3. Lyon, IARC Press, 2000, pp 105-119.

14 Odze RD, Krieken JH, Riddell RH, et al: Premalignant lesions of the digestive system; in Bosman FT, Carneiro F, Hruban RH, et al (eds): WHO Classification of Tumors of the Digestive System, ed 4. Lyon, IARC Press, 2010, pp 132-146.

15 Xu F, Xu J, Lou Z, Di M, Wang F, Hu H, Lai M: Micropapillary component in colorectal carcinoma is associated with lymph node metastasis in T1 and T2 stages and decreased survival time in TNM stages I and II. Am J Surg Pathol 2009;33:1287-1292.

16 Ogawa T, Yoshida T, Tsuruta T, Tokuyama W, Adachi S, Kikuchi M, Mikami T, Saigenji K, Okayasu I: Tumor budding is predictive of lymphatic involvement and lymph node metastases in submucosal invasive colorectal adenocarcinomas and in non-polypoid compared with polypoid growths. Scand J Gastroenterol 2009;44:605614. 
17 Tanaka M, Hashiguchi Y, Ueno H, Hase K, Mochizuki H: Tumor budding at the invasive margin can predict patients at high risk of recurrence after curative surgery for stage II, T3 colon cancer. Dis Colon Rectum 2003; 46:1054-1059.

18 Xu FY, Dong JK, Zhu YM, Qu MJ, Wang FJ, Jin YS, Ren GP, Lai MD: Study on independent factors on the prognosis of colorectal carcinoma: TNM stage, tumor budding, perineural invasion, peritumoral-lymphocytic infiltration and urine glucose (in Chinese). Zhonghua Liu Xing Bing Xue Za Zhi 2005;26:366-369.

19 Engstrom PF, Arnoletti JP, Benson AB 3rd, Chen YJ, Choti MA, Cooper HS, Covey A, Dilawari RA, Early DS, Enzinger PC, Fakih MG, Fleshman J Jr, Fuchs C, Grem JL, Kiel K, Knol JA, Leong LA, Lin E, Mulcahy MF, Rao S, Ryan DP, Saltz L, Shibata D, Skibber JM, Sofocleous C, Thomas J, Venook AP, Willett C; National Comprehensive Cancer Network: NCCN Clinical Practice Guidelines in Oncology: colon cancer. J Natl Compr Canc Netw 2009; 7:778-831.

20 Morson BC: Gastrointestinal Pathology, ed 2. Oxford, Blackwell Scientific Publications, 1979, pp 607-609, 637-638.

21 Bosman FT, Carneiro F, Hruban RH, Theise ND: WHO Classification of Tumours of the Digestive System, ed 4. Lyon, IARC Press, 2010, p 147.

22 Lai MD, Teng XD, Xu FY: Consensus and dispute in histopathology of gastrointestinal tract (in Chinese). Zhonghua Bing Li Xue Za Zhi 2011;40:289-291.

-23 U.S. Preventive Services Task Force: Screening for colorectal cancer: U.S. Preventive Services Task Force recommendation statement. Ann Intern Med 2008;149:627-637.

-24 Lieberman DA, Weiss DG; Veterans Affairs Cooperative Study Group 380: One-time screening for colorectal cancer with combined fecal occult-blood testing and examination of the distal colon. N Engl J Med 2001;345: 555-560.

25 Allison JE, Tekawa IS, Ransom LJ, Adrain AL: A comparison of fecal occult-blood tests for colorectal-cancer screening. N Engl J Med 1996;334:155-159.

-26 Allison JE, Sakoda LC, Levin TR, Tucker JP, Tekawa IS, Cuff T, Pauly MP, Shlager L, Palitz AM, Zhao WK, Schwartz JS, Ransohoff DF, Selby JV: Screening for colorectal neoplasms with new fecal occult blood tests: update on performance characteristics. J Natl Cancer Inst 2007;99:1462-1470.

27 Meng W, Cai SR, Zhou L, Dong Q, Zheng S, Zhang SZ: Performance value of high risk factors in colorectal cancer screening in China. World J Gastroenterol 2009;15:6111-6116.

28 Zhang YL, Zhou DY: The important effect in early diagnosis of colorectal cancer based on colonoscopy (in Chinese). World Chin J Digest 2003;11:640-642.

-29 Hilsden R, Rostom A: Colorectal cancer screening using flexible sigmoidoscopy: United Kingdom study demonstrates significant incidence and mortality benefit. Can J Gastroenterol 2010;24:479-480.

-30 Zheng S, Liu XY, Ding KF, Wang LB, Qiu PL, Ding XF, Shen YZ, Shen GF, Sun QR, Li WD, Dong Q, Zhang SZ: Reduction of the incidence and mortality of rectal cancer by polypectomy: a prospective cohort study in Haining County. World J Gastroenterol 2002;8:488-492.

31 Chen K, Yu WP, Ma XY, Yao KY, Li QL: Quantitative assessment of individual risk and population screening for colon and rectal cancer (in Chinese). Tumor 2005;25:66-70.

32 Chen K, Jiao DA, Yu H: An applied study on the method of multi-factorial quantitative-risk assessment (MFQRA) for mass screening of colorectal cancer (in Chinese). Zhonghua Zhong Liu Za Zhi 1993;15:37-40.

-33 Harnett SJ, Wong SK, Lackey GW: Opportunistic GP-based bowel cancer screening. Med J Aust 2003;178: 92-93.

34 Ministry of Health, People's Republic of China: Chinese Health Statistical Digest [S], 2007 (in Chinese).

35 Ma XY, Li QL, Ma WL: Cost estimation and control of colorectal cancer screening (in Chinese). China Cancer 2011;20:422-424.

-36 Han Y, Wu ZT, Li SR: Introduction of a new screening model for opportunistic screening of colorectal neoplasm (in Chinese). Zhonghua Nei Ke Za Zhi 2008;47:725-726.

37 Han Y, Wu ZT, Li SR, Sheng JQ: Results analysis of opportunistic screening of 2,756 cases of colorectal neoplasm (in Chinese). Chin J Misdiagn 2008;8:2130.

38 Han Y, Wu ZT, Sheng JQ, Li YH, Wang BX, Gao P, Li SR: Clinical application of opportunistic screening of colorectal neoplasm (in Chinese). Zhonghua Nei Ke Za Zhi 2010;49:618-619.

-39 Chu E: Colorectal cancer screening and early detection. Clin Colorectal Cancer 2010;9:75-76.

40 Li SR: The current screening policy of colorectal cancer in China (in Chinese). Chin J Gastroenterol Hepatol 2008;17:261-262.

41 Hobbs FD, Cherry RC, Fielding JW, Pike L, Holder R: Acceptability of opportunistic screening for occult gastrointestinal blood loss. BMJ 1992;304:483-486.

-42 Yeoh KG, Chew L, Wang SC: Cancer screening in Singapore, with particular reference to breast, cervical and colorectal cancer screening. J Med Screen 2006;13(suppl 1):S14-S19.

43 Wu ZT, Wang ZH: Reassessment on the screening of colorectal neoplasm by the 'sequential fecal occult blood test' (in Chinese). J Pract Oncol 1995;10:223-224.

44 Li SR: Samples analysis of colorectal cancer in in some parts of Huabei area in China (in Chinese). Med J Chin People's Liberation Army 1990;15:30-32.

45 Li SR, Tian SL, Wu ZT, Han Y, Sheng JQ, Gao G, Xia CH, Cao JB, Chen ZM, Wang ZH, Li YJ: Application of sequential fecal occult blood test in consecutive screening of colorectal cancer for natural population (in Chinese). World Chin J Digest 2004;12:137-139. 
Sheng JQ, Wu ZT, Wang ZH, Lu JG, Cui XJ, Han Y, Li SR: A cohort study of consecutive colorectal cancer screening using sequential fecal occult blood test in a natural population: results of 19 years study (in Chinese). Chin J Gastroenterol 2008;13:4-8.

47 Zheng S, Zhang SZ, Cai SR, Huang YQ: Protocol and practice for colorectal cancer screening (in Chinese). China Cancer 2009;18:700-704.

48 Zheng S, Yang G, Yu H, Qiu PL, Zhang X, Zhou L: Reassessment on the screening methods of early and asymptomatic colorectal cancer (in Chinese). J Med Res 1992;21:30-31.

49 Zheng S: Etiology, screening, early detection and treatment of colorectal cancer in high risk areas (in Chinese). China Cancer 1996;5:18-19.

-50 Engel C, Rahner N, Schulmann K, Holinski-Feder E, Goecke TO, Schackert HK, Kloor M, Steinke V, Vogelsang H, Moslein G, Gorgens H, Dechant S, von Knebel Doeberitz M, Ruschoff J, Friedrichs N, Buttner R, Loeffler M, Propping P, Schmiegel W: Efficacy of annual colonoscopic surveillance in individuals with hereditary nonpolyposis colorectal cancer. Clin Gastroenterol Hepatol 2010;8:174-182.

-51 Capelle LG, Van Grieken NC, Lingsma HF, Steyerberg EW, Klokman WJ, Bruno MJ, Vasen HF, Kuipers EJ: Risk and epidemiological time trends of gastric cancer in Lynch syndrome carriers in the Netherlands. Gastroenterology 2010;138:487-492.

-52 Burt R, Neklason DW: Genetic testing for inherited colon cancer. Gastroenterology 2005;128:1696-1716.

53 NCCN Guidelines Version 2. Colorectal Cancer Screening 2011.

54 Eaden JA, Abrams KR, Mayberry JF: The risk of colorectal cancer in ulcerative colitis: a meta-analysis. Gut 2001;48:526-535.

55 Obrador A, Ginard D, Barranco L: Review article: colorectal cancer surveillance in ulcerative colitis - what should we be doing? Aliment Pharmacol Ther 2006;24(suppl 3):56-63.

56 Efthymiou M, Taylor AC, Kamm MA: Cancer surveillance strategies in ulcerative colitis: the need for modernization. Inflamm Bowel Dis 2011;17:1800-1813.

57 National Institute for Health and Clinical Excellence: Colonoscopic surveillance for prevention of colorectal cancer in people with ulcerative colitis, Crohn's disease or adenomas. NICE clinical guideline 118. March 2011.

-58 Rutter MD, Saunders BP, Wilkinson KH, Rumbles S, Schofield G, Kamm MA, Williams CB, Price AB, Talbot IC, Forbes A: Thirty-year analysis of a colonoscopic surveillance program for neoplasia in ulcerative colitis. Gastroenterology 2006;130:1030-1038.

-59 Velayos FS, Liu L, Lewis JD, Allison JE, Flowers N, Hutfless S, Abramson O, Perry GS, Herrinton LJ: Prevalence of colorectal cancer surveillance for ulcerative colitis in an integrated health care delivery system. Gastroenterology 2010;139:1511-1518.

-60 Brackmann S, Andersen SN, Aamodt G, Langmark F, Clausen OP, Aadland E, Fausa O, Rydning A, Vatn MH: Relationship between clinical parameters and the colitis-colorectal cancer interval in a cohort of patients with colorectal cancer in inflammatory bowel disease. Scand J Gastroenterol 2009;44:46-55.

61 Delaunoit T, Limburg PJ, Goldberg RM, Lymp JF, Loftus EV Jr: Colorectal cancer prognosis among patients with inflammatory bowel disease. Clin Gastroenterol Hepatol 2006;4:335-342.

62 Allen PB, Kamm MA, De Cruz P, Desmond PV: Dysplastic lesions in ulcerative colitis: changing paradigms. Inflamm Bowel Dis 2010;16:1978-1983.

63 Averboukh F, Ziv Y, Kariv Y, Zmora O, Dotan I, Klausner JM, Rabau M, Tulchinsky H: Colorectal carcinoma in inflammatory bowel disease: a comparison between Crohn's and ulcerative colitis. Colorectal Dis 2011;13: 1230-1236.

64 Ullman T, Odze R, Farraye FA: Diagnosis and management of dysplasia in patients with ulcerative colitis and Crohn's disease of the colon. Inflamm Bowel Dis 2009;15:630-638.

65 Ohnishi T, Watanabe T, Nozawa H, Kitayama J, Nagawa H: Telomerase activity of blood samples and recurrence of colorectal cancer. Hepatogastroenterology 2008;55:1513-1518.

66 Lledo SM, Garcia-Granero E, Dasi F, Ripoli R, Garcia SA, Cervantes A, Alino SF: Real time quantification in plasma of human telomerase reverse transcriptase (hTERT) mRNA in patients with colorectal cancer. Colorectal Dis 2004;6:236-242.

-67 Sidransky D, Tokino T, Hamilton SR, Kinzler KW, Levin B, Frost P, Vogelstein B: Identification of ras oncogene mutations in the stool of patients with curable colorectal tumors. Science 1992;256:102-105.

68 Nollau P, Moser C, Weinland G, Wagener C: Detection of K-ras mutations in stools of patients with colorectal cancer by mutant-enriched PCR. Int J Cancer 1996;66:332-336.

69 Smith-Ravin J, England J, Talbot IC, Bodmer W: Detection of c-Ki-ras mutations in faecal samples from sporadic colorectal cancer patients. Gut 1995;36:81-86.

70 Eguchi S, Kohara N, Komuta K, Kanematsu T: Mutations of the p53 gene in the stool of patients with resectable colorectal cancer. Cancer 1996;77(suppl 8):1707-1710.

-71 Traverso G, Shuber A, Levin B, Johnson C, Olsson L, Schoetz DJ Jr, Hamilton SR, Boynton K, Kinzler KW, Vogelstein B: Detection of APC mutations in fecal DNA from patients with colorectal tumors. N Engl J Med 2002;346: 311-320.

72 Sheng JQ, Li SR, Wu ZT, Xia CH, Wu X, Chen J, Rao J: Transferrin dipstick as a potential novel test for colon cancer screening: a comparative study with immuno fecal occult blood test. Cancer Epidemiol Biomarkers Prev 2009;18:2182-2185.

73 Rajapaksa RC, Macari M, Bini EJ: Prevalence and impact of extracolonic findings in patients undergoing CT colonography. J Clin Gastroenterol 2004;38:767-771. 
74 Pickhardt PJ, Hassan C, Halligan S, Marmo R: Colorectal cancer: CT colonography and colonoscopy for detection - systematic review and meta-analysis. Radiology 2011;259:393-405.

75 Belsey J, Epstein 0, Heresbach D: Systematic review: oral bowel preparation for colonoscopy. Aliment Pharmacol Ther 2007;25:373-384.

76 Harewood GC, Sharma VK, de Garmo P: Impact of colonoscopy preparation quality on detection of suspected colonic neoplasia. Gastrointest Endosc 2003;58:76-79.

-77 Froehlich F, Wietlisbach V, Gonvers JJ, Burnand B, Vader JP: Impact of colonic cleansing on quality and diagnostic yield of colonoscopy: the European Panel of Appropriateness of Gastrointestinal Endoscopy European multicenter study. Gastrointest Endosc 2005;61:378-384.

78 Huang YL, Zhi FC, Huang LW, Gong W, Liu SD, Su BZ, Zhang YL, Jiang B: Rate and risk factors of missed diagnosis of colorectal adenoma with colonoscopy (in Chinese). Chin J Digest Endosc 2010,27:281-286.

-79 Simmons DT, Harewood GC, Baron TH, Petersen BT, Wang KK, Boyd-Enders F, Ott BJ: Impact of endoscopist withdrawal speed on polyp yield: implications for optimal colonoscopy withdrawal time. Aliment Pharmacol Ther 2006;24:965-971.

80 The Paris endoscopic classification of superficial neoplastic lesions: esophagus, stomach, and colon: November 30 to December 1, 2002. Gastrointest Endosc 2003;58(suppl 6):S3-S43.

81 Jiang B: Magnifying endoscopy with dye-spraying technique is a important method to detect early colorectal cancer (in Chinese). Chin J Digest Endosc 2005;22:293-294.

82 Jiang B, Zhi FC, Liu SD, Han YJ, Pan DS, Zhou D, Wan TM, Zhou DY: Pit pattern and endoscopic mucosal resection in diagnosis and treatment of colorectal tumors (in Chinese). Zhonghua Yi Xue Za Zhi 2003;83:294-297.

83 Kudo S: Early Colorectal Cancer-Detection of Depressed Types of Colorectal Carcinoma. Tokyo, Igaku-Shoin Medical Publisher Inc., 1996, pp 50-51.

84 Gastroenterology Group of Chinese Society of Digestive Endoscopy, Jiang B, Liu SL: Consensus on endoscopic diagnosis and managements of early colorectal carcinoma (Tianjin, August 30, 2008) (in Chinese). Chin J Digest Endosc 2008;25:321-324.

85 Togashi K, Hewett DG, Whitaker DA, Hume GE, Francis L, Appleyard MN: The use of acetic acid in magnification chromocolonoscopy for pit pattern analysis of small polyps. Endoscopy 2006;38:613-616.

-86 Matsuda T, Fujii T, Saito Y, Nakajima T, Uraoka T, Kobayashi N, Ikehara H, Ikematsu H, Fu KI, Emura F, Ono A, Sano Y, Shimoda T, Fujimori T: Efficacy of the invasive/non-invasive pattern by magnifying chromoendoscopy to estimate the depth of invasion of early colorectal neoplasms. Am J Gastroenterol 2008;103:2700-2706.

87 Sakamoto T, Saito Y, Nakajima T, Matsuda T: Comparison of magnifying chromoendoscopy and narrow-band imaging in estimation of early colorectal cancer invasion depth: a pilot study. Dig Endosc 2011;23:118-123.

-88 Saitoh Y, Obara T, Watari J, Nomura M, Taruishi M, Orii Y, Taniguchi M, Ayabe T, Ashida T, Kohgo Y: Invasion depth diagnosis of depressed type early colorectal cancers by combined use of videoendoscopy and chromoendoscopy. Gastrointest Endosc 1998;48:362-370.

-89 Sano Y, Horimatsu T, Fu KI, Katagiri A, Muto M, Ishikawa H: Magnifying observation of micro-vascular architecture of colorectal lesions using narrow band imaging system. Dig Endosc 2006;18(suppl 1):S44-S51.

$\checkmark 90$ Wada Y, Kudo SE, Misawa M, Ikehara N, Hamatani S: Vascular pattern classification of colorectal lesions with narrow band imaging magnifying endoscopy. Dig Endosc 2011;23(suppl 1):106-111.

-91 Kanao H, Tanaka S, Oka S, Hirata M, Yoshida S, Chayama K, Kanao H, Tanaka S, Oka S, Hirata M, Yoshida S, Chayama K: Narrow-band imaging magnification predicts the histology and invasion depth of colorectal tumors. Gastrointest Endosc 2009;69:631-636.

$\$ 92$ Puli SR, Bechtold ML, Reddy JB, Choudhary A, Antillon MR: Can endoscopic ultrasound predict early rectal cancers that can be resected endoscopically? A meta-analysis and systematic review. Dig Dis Sci 2010;55: 1221-1229.

-93 Hoffman A, Sar F, Goetz M, Tresch A, Mudter J, Biesterfeld S, Galle PR, Neurath MF, Kiesslich R: High definition colonoscopy combined with i-Scan is superior in the detection of colorectal neoplasias compared with standard video colonoscopy: a prospective randomized controlled trial. Endoscopy 2010;42:827-833.

$\$ 4$ Lee CK, Lee SH, Hwangbo Y: Narrow-band imaging versus I-Scan for the real-time histological prediction of diminutive colonic polyps: a prospective comparative study by using the simple unified endoscopic classification. Gastrointest Endosc 2011;74:603-609.

95 Hoffman A, Kagel C, Goetz M, Tresch A, Mudter J, Biesterfeld S, Galle PR, Neurath MF, Kiesslich R: Recognition and characterization of small colonic neoplasia with high-definition colonoscopy using i-Scan is as precise as chromoendoscopy. Dig Liver Dis 2011;42:45-50.

96 Kiesslich R, Burg J, Vieth M, Gnaendiger J, Enders M, Delaney P, Polglase A, McLaren W, Janell D, Thomas S, Nafe B, Galle PR, Neurath MF: Confocal laser endoscopy for diagnosing intraepithelial neoplasias and colorectal cancer in vivo. Gastroenterology 2004;127:706-713.

-97 Kashida H, Kudo SE: Early colorectal cancer: concept, diagnosis, and management. Int J Clin Oncol 2006;11: 1-8.

98 Cappell MS, Friedel D: The role of sigmoidoscopy and colonoscopy in the diagnosis and management of lower gastrointestinal disorders: technique, indications, and contraindications. Med Clin North Am 2002;86:12171252.

\$9 Tanaka S, Oka S, Chayama K: Colorectal endoscopic submucosal dissection: present status and future perspective, including its differentiation from endoscopic mucosal resection. J Gastroenterol 2008;43:641651. 
Fang et al.: Consensus on the Prevention, Screening, Early Diagnosis and Treatment of Colorectal Tumors in China

100 Tanaka S, Haruma K, Oka S, Takahashi R, Kunihiro M, Kitadai Y, Yoshihara M, Shimamoto F, Chayama K: Clinicopathologic features and endoscopic treatment of superficially spreading colorectal neoplasms larger than 20 mm. Gastrointest Endosc 2001;54:62-66.

101 Huang Y, Liu S, Gong W, Zhi F, Pan D, Jiang B: Clinicopathologic features and endoscopic mucosal resection of laterally spreading tumors: experience from China. Int J Colorectal Dis 2009;24:1441-1450.

102 Hu JJ, Wang X, Pan X, Geng Y, Zhang Y, Jiang B: An increase in the diagnosis rate of early colorectal cancer by sample targeting using stereomicroscopy: a two-year experience with 196 cases. Hepatogastroenterology 2008;55:1578-1583.

103 Martinez ME, Sampliner R, Marshall JR, Bhattacharyya AK, Reid ME, Alberts DS: Adenoma characteristics as risk factors for recurrence of advanced adenomas. Gastroenterology 2001;120:1077-1083.

-104 Martinez ME, Baron JA, Lieberman DA, Schatzkin A, Lanza E, Winawer SJ, Zauber AG, Jiang R, Ahnen DJ, Bond JH, Church TR, Robertson DJ, Smith-Warner SA, Jacobs ET, Alberts DS, Greenberg ER: A pooled analysis of advanced colorectal neoplasia diagnoses after colonoscopic polypectomy. Gastroenterology 2009;136:832841.

105 Gao QY, Chen HM, Sheng JQ, Zheng P, Yu CG, Jiang B, Fang JY: The first year follow-up after colorectal adenoma polypectomy is important: a multiple-center study in symptomatic hospital-based individuals in China. Front Med China 2010;4:436-442.

106 Kaminski MF, Regula J, Kraszewska E, Polkowski M, Wojciechowska U, Didkowska J, Zwierko M, Rupinski M, Nowacki MP, Butruk E: Quality indicators for colonoscopy and the risk of interval cancer. N Engl J Med 2010; 362:1795-1803.

107 Sawhney MS, Farrar WD, Gudiseva S, Nelson DB, Lederle FA, Rector TS, Bond JH: Microsatellite instability in interval colon cancers. Gastroenterology 2006;131:1700-1705.

108 Pabby A, Schoen RE, Weissfeld JL, Burt R, Kikendall JW, Lance P, Shike M, Lanza E, Schatzkin A: Analysis of colorectal cancer occurrence during surveillance colonoscopy in the dietary Polyp Prevention Trial. Gastrointest Endosc 2005;61:385-391.

109 Winawer SJ, Zauber AG, Fletcher RH, Stillman JS, O’Brien MJ, Levin B, Smith RA, Lieberman DA, Burt RW, Levin TR, Bond JH, Brooks D, Byers T, Hyman N, Kirk L, Thorson A, Simmang C, Johnson D, Rex DK: Guidelines for colonoscopy surveillance after polypectomy: a consensus update by the US Multi-Society Task Force on Colorectal Cancer and the American Cancer Society. Gastroenterology 2006;130:1872-1885.

110 Fang JY: Chemoprophylaxis for colorectal cancer: opportunities and challenges (in Chinese). Zhonghua Nei Ke Za Zhi 2009;48:93-94.

111 Sung JJ, Lau JY, Goh KL, Leung WK: Increasing incidence of colorectal cancer in Asia: implications for screening. Lancet Oncol 2005;6:871-876.

112 Heresbach D, Barrioz T, Lapalus MG, Coumaros D, Bauret P, Potier P, Sautereau D, Boustiere C, Grimaud JC, Barthelemy C, See J, Serraj I, D’Halluin PN, Branger B, Ponchon T: Miss rate for colorectal neoplastic polyps: a prospective multicenter study of back-to-back video colonoscopies. Endoscopy 2008;40:284-290.

113 Fang JY, Shen L, Sun DF: High risk group of colorectal cancer: the key points for screening and prevention (in Chinese). Zhonghua Yi Xue Za Zhi 2009;89:1369-1371.

114 Fang JY: Make an intensive study of diagnosis and treatment for colorectal adenoma (in Chinese). Chin J Digest 2010;30:433-435.

115 Fang JY: Oncogenesis and prevention of colorectal adenomas (in Chinese). Chin J Digest 2011;31:136-137.

116 Thompson PA, Gerner EW: Current concepts in colorectal cancer prevention. Expert Rev Gastroenterol Hepatol 2009;3:369-382.

117 Sporn MB, Dunlop NM, Newton DL, Smith JM: Prevention of chemical carcinogenesis by vitamin A and its synthetic analogs (retinoids). Fed Proc 1976;35:1332-1338.

118 Bingham SA, Day NE, Luben R, Ferrari P, Slimani N, Norat T, Clavel-Chapelon F, Kesse E, Nieters A, Boeing H, Tjonneland A, Overvad K, Martinez C, Dorronsoro M, Gonzalez CA, Key TJ, Trichopoulou A, Naska A, Vineis P, Tumino R, Krogh V, Bueno-de-Mesquita HB, Peeters PH, Berglund G, Hallmans G, Lund E, Skeie G, Kaaks R, Riboli E: Dietary fibre in food and protection against colorectal cancer in the European Prospective Investigation into Cancer and Nutrition (EPIC): an observational study. Lancet 2003;361:1496-1501.

119 Peters U, Sinha R, Chatterjee N, Subar AF, Ziegler RG, Kulldorff M, Bresalier R, Weissfeld JL, Flood A, Schatzkin A, Hayes RB: Dietary fibre and colorectal adenoma in a colorectal cancer early detection programme. Lancet 2003;361:1491-1495.

120 Jacobs ET, Haussler MR, Martinez ME: Vitamin D activity and colorectal neoplasia: a pathway approach to epidemiologic studies. Cancer Epidemiol Biomarkers Prev 2005;14:2061-2063.

121 Pufulete M: Intake of dairy products and risk of colorectal neoplasia. Nutr Res Rev 2008;21:56-67.

122 Mizoue T, Kimura Y, Toyomura K, Nagano J, Kono S, Mibu R, Tanaka M, Kakeji Y, Maehara Y, Okamura T, Ikejiri K, Futami K, Yasunami Y, Maekawa T, Takenaka K, Ichimiya H, Imaizumi N: Calcium, dairy foods, vitamin D, and colorectal cancer risk: the Fukuoka Colorectal Cancer Study. Cancer Epidemiol Biomarkers Prev 2008; $17: 2800-2807$

123 de Vogel S, Dindore V, van Engeland M, Goldbohm RA, van den Brandt PA, Weijenberg MP: Dietary folate, methionine, riboflavin, and vitamin B-6 and risk of sporadic colorectal cancer. J Nutr 2008;138:2372-2378.

124 Lee JE, Willett WC, Fuchs CS, Smith-Warner SA, Wu K, Ma J, Giovannucci E: Folate intake and risk of colorectal cancer and adenoma: modification by time. Am J Clin Nutr 2011;93:817-825. 
125 Alberts DS, Martinez ME, Roe DJ, Guillen-Rodriguez JM, Marshall JR, van Leeuwen JB, Reid ME, Ritenbaugh C, Vargas PA, Bhattacharyya AB, Earnest DL, Sampliner RE: Lack of effect of a high-fiber cereal supplement on the recurrence of colorectal adenomas. Phoenix Colon Cancer Prevention Physicians' Network. N Engl J Med 2000;342:1156-1162.

126 Schatzkin A, Lanza E, Corle D, Lance P, Iber F, Caan B, Shike M, Weissfeld J, Burt R, Cooper MR, Kikendall JW, Cahill J: Lack of effect of a low-fat, high-fiber diet on the recurrence of colorectal adenomas. Polyp Prevention Trial Study Group. N Engl J Med 2000;342:1149-1155.

127 Crott JW, Choi SW, Ordovas JM, Ditelberg JS, Mason JB: Effects of dietary folate and aging on gene expression in the colonic mucosa of rats: implications for carcinogenesis. Carcinogenesis 2004;25:69-76.

128 Wolpin BM, Wei EK, Ng K, Meyerhardt JA, Chan JA, Selhub J, Giovannucci EL, Fuchs CS: Prediagnostic plasma folate and the risk of death in patients with colorectal cancer. J Clin Oncol 2008;26:3222-3228.

129 Cole BF, Baron JA, Sandler RS, Haile RW, Ahnen DJ, Bresalier RS, McKeown-Eyssen G, Summers RW, Rothstein RI, Burke CA, Snover DC, Church TR, Allen JI, Robertson DJ, Beck GJ, Bond JH, Byers T, Mandel JS, Mott LA, Pearson LH, Barry EL, Rees JR, Marcon N, Saibil F, Ueland PM, Greenberg ER: Folic acid for the prevention of colorectal adenomas: a randomized clinical trial. JAMA 2007;297:2351-2359.

130 Logan RF, Grainge MJ, Shepherd VC, Armitage NC, Muir KR: Aspirin and folic acid for the prevention of recurrent colorectal adenomas. Gastroenterology 2008;134:29-38.

131 Ibrahim EM, Zekri JM: Folic acid supplementation for the prevention of recurrence of colorectal adenomas: metaanalysis of interventional trials. Med Oncol 2010;27:915-918.

132 Stevens VL, McCullough ML, Sun J, Jacobs EJ, Campbell PT, Gapstur SM: High levels of folate from supplements and fortification are not associated with increased risk of colorectal cancer. Gastroenterology 2011;141: 98-105.

133 Lynch PM: Prevention of colorectal cancer in high-risk populations: the increasing role for endoscopy and chemoprevention in FAP and HNPCC. Digestion 2007;76:68-76.

134 Chan AT, Giovannucci EL, Meyerhardt JA, Schernhammer ES, Wu K, Fuchs CS: Aspirin dose and duration of use and risk of colorectal cancer in men. Gastroenterology 2008;134:21-28.

135 Dubé C, Rostom A, Lewin G, Tsertsvadze A, Barrowman N, Code C, Sampson M, Moher D; U.S. Preventive Services Task Force: The use of aspirin for primary prevention of colorectal cancer: a systematic review prepared for the U.S. Preventive Services Task Force. Ann Intern Med 2007;146:365-375.

136 Cook NR, Lee IM, Gaziano JM, Gordon D, Ridker PM, Manson JE, Hennekens CH, Buring JE: Low-dose aspirin in the primary prevention of cancer: the Women's Health Study: a randomized controlled trial. JAMA 2005;294: 47-55.

137 Din FV, Theodoratou E, Farrington SM, Tenesa A, Barnetson RA, Cetnarskyj R, Stark L, Porteous ME, Campbell H, Dunlop MG: Effect of aspirin and NSAIDs on risk and survival from colorectal cancer. Gut 2010;59:16701679.

138 Winawer SJ, Zauber AG: Colonoscopic polypectomy and the incidence of colorectal cancer. Gut 2001;48:753754.

139 Bertagnolli MM, Eagle CJ, Zauber AG, Redston M, Solomon SD, Kim K, Tang J, Rosenstein RB, Wittes J, Corle D, Hess TM, Woloj GM, Boisserie F, Anderson WF, Viner JL, Bagheri D, Burn J, Chung DC, Dewar T, Foley TR, Hoffman N, Macrae F, Pruitt RE, Saltzman JR, Salzberg B, Sylwestrowicz T, Gordon GB, Hawk ET: Celecoxib for the prevention of sporadic colorectal adenomas. N Engl J Med 2006;355:873-884.

140 Arber N, Eagle CJ, Spicak J, Racz I, Dite P, Hajer J, Zavoral M, Lechuga MJ, Gerletti P, Tang J, Rosenstein RB, Macdonald K, Bhadra P, Fowler R, Wittes J, Zauber AG, Solomon SD, Levin B: Celecoxib for the prevention of colorectal adenomatous polyps. N Engl J Med 2006;355:885-895.

141 Baron JA, Sandler RS, Bresalier RS, Quan H, Riddell R, Lanas A, Bolognese JA, Oxenius B, Horgan K, Loftus S, Morton DG: A randomized trial of rofecoxib for the chemoprevention of colorectal adenomas. Gastroenterology 2006;131:1674-1682.

142 Bertagnolli MM: Chemoprevention of colorectal cancer with cyclooxygenase-2 inhibitors: two steps forward, one step back. Lancet Oncol 2007;8:439-443.

143 Rostom A, Dubé C, Lewin G, Tsertsvadze A, Barrowman N, Code C, Sampson M, Moher D: Nonsteroidal antiinflammatory drugs and cyclooxygenase- 2 inhibitors for primary prevention of colorectal cancer: a systematic review prepared for the U.S. Preventive Services Task Force. Ann Intern Med 2007;146:376-389.

144 Fang JY, Chen YX, Lu J, Lu R, Yang L, Zhu HY, Gu WQ, Lu LG: Epigenetic modification regulates expression of tumor-associated genes and cell cycle in human colon cancer cell lines Colo-320 and SW1116. Cell Res 2004; 13:217-226.

145 Fang JY, Xiao SD: The preventive effects of bioactive food components against colorectal cancer (in Chinese). Chin J Digest 2006;26:716-717.

146 Bhatnagar N, Li X, Chen Y, Zhou X, Garrett SH, Guo B: 3,3'-diindolylmethane enhances the efficacy of butyrate in colon cancer prevention through down-regulation of survivin. Cancer Prev Res (Phila) 2009;2:581-589.

147 Crim KC, Sanders LM, Hong MY, Taddeo SS, Turner ND, Chapkin RS, Lupton JR: Upregulation of p21Waf1/Cip1 expression in vivo by butyrate administration can be chemoprotective or chemopromotive depending on the lipid component of the diet. Carcinogenesis 2008;29:1415-1420.

148 Grau MV, Baron JA, Sandler RS, Haile RW, Beach ML, Church TR, Heber D: Vitamin D, calcium supplementation, and colorectal adenomas: results of a randomized trial. J Natl Cancer Inst 2003;95:1765-1771. 
149 Wang JL, Lin YW, Chen HM, Kong X, Hong J, Fang JY: Calcium prevents tumorigenesis in a mouse model of colorectal cancer. PLoS One 2011;6:22566.

150 Grau MV, Rees JR, Baron JA: Chemoprevention in gastrointestinal cancers: current status. Basic Clin Pharmacol Toxicol 2006;98:281-287.

151 Lu R, Wang X, Sun DF, Tian XQ, Zhao SL, Chen YX, Fang JY: Folic acid and sodium butyrate prevent tumorigenesis in a mouse model of colorectal cancer. Epigenetics 2008;3:330-335.

152 Corfe BM, Williams EA, Bury JP, Riley SA, Croucher LJ, Lai DY, Evans CA: A study protocol to investigate the relationship between dietary fibre intake and fermentation, colon cell turnover, global protein acetylation and early carcinogenesis: the FACT study. BMC Cancer 2009;9:332.

153 Hallert C, Björck I, Nyman M, Pousette A, Grännö C, Svensson H: Increasing fecal butyrate in ulcerative colitis patients by diet: controlled pilot study. Inflamm Bowel Dis 2003;9:116-121.

154 Vernia P, Monteleone G, Grandinetti G, Villotti G, Di Giulio E, Frieri G, Marcheggiano A, Pallone F, Caprilli R, Torsoli A: Combined oral sodium butyrate and mesalazine treatment compared to oral mesalazine alone in ulcerative colitis: randomized, double-blind, placebo-controlled pilot study. Dig Dis Sci 2000;45:976-981.

155 Uraoka T, Saito Y, Ikematsu H, Yamamoto K, Sano Y: Sano’s capillary pattern classification for narrow-band imaging of early colorectal lesions. Dig Endosc 2011;23(suppl 1):112-115.

156 Cairns SR, Scholefield JH, Steele RJ, Dunlop MG, Thomas HJ, Evans GD, Eaden JA, Rutter MD, Atkin WP, Saunders BP, Lucassen A, Jenkins P, Fairclough PD, Woodhouse CR: Guidelines for colorectal cancer screening and surveillance in moderate and high risk groups (update from 2002). Gut 2010;59:666-689. 